Abbreviated Key Title: Sch J Med Case Rep

ISSN 2347-9507 (Print) | ISSN 2347-6559 (Online)

Journal homepage: https://saspublishers.com

\title{
An Interesting Case of Bilateral Breast Filariasis
}

Pawan Trivedi ${ }^{*}$, Vinay Kumar Jain ${ }^{2}$, Santosh Kumar Jain ${ }^{2}$, Neelam Jain ${ }^{2}$, Swati Jain ${ }^{2}$

${ }^{1}$ Consultant Pathologist, Ultra Diagnostic and Research Centre, Barabanki, UP, India

${ }^{2}$ Consultant, Jain Nursing Home, Barabanki, UP, India

DOI: $10.36347 /$ sjmcr.2021.v09i02.011

| Received: 07.02.2021 | Accepted: 17.02.2021 | Published: 19.02.2021

*Corresponding author: Pawan Trivedi

Abstract

Case Report

Filariasis is a common disease in India, however it occurs rarely at extranodal sites specially breast. Present case is of young female with painless lump in the both breasts for last one year. Provisional clinical diagnosis made was bilateral breast fibroadenoma. On aspiration cytology, the smears from bilateral breast lumps showed numerous microfilaria larvae along with fair number of mature lymphocytes in the background. Hence, a confirmed diagnosis of Filariasis, both breast was made. A simple and effective investigation, FNAC was able to avoid an unnecessary invasive, more painful and time taking procedure in this patient.

Keywords: FNAC, Bilateral Breast Lump, Filriasis, Wuchereria bancrofti.

Copyright (C) 2021 The Author(s): This is an open-access article distributed under the terms of the Creative Commons Attribution 4.0 International License (CC BY-NC 4.0) which permits unrestricted use, distribution, and reproduction in any medium for non-commercial use provided the original author and source are credited.

\section{INTRODUCTION}

Filariasis is a common and major comorbid condition. In India, the most common cause of filariasis is Wuchereria bancrofti. Commonly affected sites are lymph nodes [1]. Extranodal sites like breast are uncommon sites to be involved by filaria [2-5]. Other locations such as skin, soft tissue, epididymis, spermatic cord, lymph nodes, pleural and peritoneal fluids, hydrocele fluid, bone marrow etc., are the reported sites for filarial infestations [6-9]. Filariasis of bilateral breast is less known and a rare finding.

\section{CASE Report}

A young female of 18year age presented with the chief complaint of slow growing, painless lump in both breasts along with off and on fever for one year. There was no history of trauma, loss of appetite, cough, evening rise of fever, weight loss, or nipple discharge. Family history for breast carcinoma was absent. On physical examination, there was no visible nipple discharge, nipple retraction or any skin changes. On palpation a firm, mobile, non-tender mass was felt in both breasts. Size of the bilateral lumps were approximately $1 \mathrm{~cm}$ in largest dimension each, located in the upper outer quadrant of right breast and retroareolar region of left. There was no significant lymphadenopathy of axilla, neck or inguinal area.

FNA was performed using a $24 \mathrm{G}$ needle which yielded scanty, clear watery aspirate from bilateral lumps and smeared on glass slides. Smears were wet fixed immediately in $95 \%$ ethanol and were subsequently stained with Leishman-Giemsa and PAP stain. Smears from both breasts showed occasional tiny clusters of ductal cells and numerous Microfilaria larvae. Background predominantly showed scattered population of mature lymphocytes (Figure $1 \& 2$ ). A cyto-morphological diagnosis of Filariasis both breast was made.

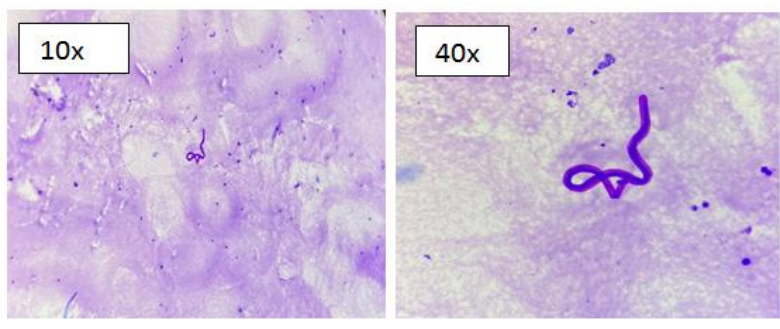

Fig-1: LG stained smears showing Microfilaria larva and scattered mature lymphocytes in the background (Right breast)

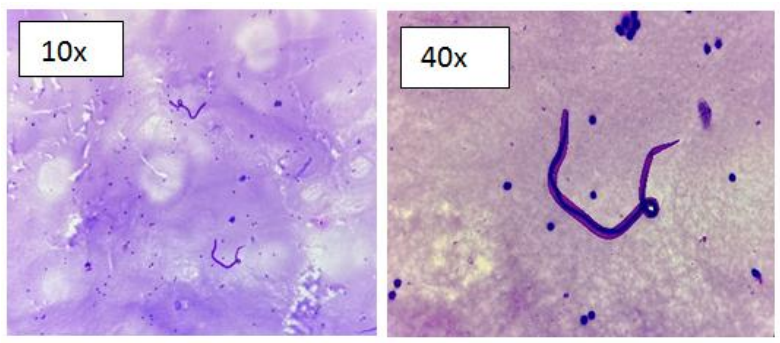

Fig-2: LG stained smears showing Microfilaria larva and scattered mature lymphocytes in the background (Left breast) 


\section{DiscuSSION}

Prevalence of filariasis is high in Asia and Africa, however it occurs in most parts of the world. In India and other Asian countries, the burden of disease is mainly because of Wuchereria bancrofti. Other filaria causative parasites are Brugia malayi and Brugia timori [10]. Lymph nodes and lymphatic vessels are main target sites of Wuchereria bancrofti. Filariasis of female breast is rare and hence not many cases have been reported [2-5]. In most of reported cases, the main causative agent for breast filariasis is Wuchereria bancrofti. In breast, the most common location is upper outer quadrant which was observed in right breast of our case. Several case reports have mentioned retro- or peri-areolar location also which was observed in left breast of our case [4]. As the larvae infests the breast lymphatics causing lymphangitis and disruption of lymphatic drainage, result in oedema of skin with peau d'orange and may mimic carcinoma breast $[1,11]$. On smears, parasites along with eosinophils as major inflammatory cell, is the predominant finding. However, no eosinophils were found in our case. FNAC is effective and less invasive tool and has been used to diagnose cases of filarial nodule in breast [2-5]. Thus, in patients with mass lesions, FNAC can be used as an effective diagnostic tool.

\section{CONCLUSION}

FNA smear is very sensitive to demonstrate filarial parasite and also a reliable mode of diagnosis that prevents unnecessary surgical intervention in breast lump cases.

\section{REFERENCES}

1. Lang AP, Luchsinger IS, Rawling EG. Filariasis of the breast. Archives of pathology \& laboratory medicine. 1987 Aug;111(8):757-9.
2. Kapila K, Verma K. Diagnosis of parasites in fine needle breast aspirates. Acta cytologica. $1996 \mathrm{Jul}$ 1;40(4):653-6.

3. Rukmangadha N, Shanthi V, Kiran CM, Kumari NP, Bai SJ. Breast filariasis diagnosed by fine needle aspiration cytology--a case report. Indian journal of pathology \& microbiology. 2006 Apr;49(2):243-4.

4. Pant I, Singh PN, Singh SN. Filariasis of breast: A report of two cases: an unusual site to be involved. J Cytol. 2003;20:206-7.

5. Hippargi SB, Kittur SK, Yelikar BR. Filariasis of the breast, diagnosed on fine needle aspiration cytology. J Cytol. 2007; 24:103-4.

6. Mitra SK, Mishra RK, Verma P. Cytological diagnosis of microfilariae in filariasis endemic areas of eastern Uttar Pradesh. J Cytol. 2009; 26(1): 11-14.

7. Sujathan K, Abraham EK. Breast lump suspected for carcinoma diagnosed as filarial granuloma by FNAC: A report of two cases. Austral-Asian Journal of Cancer. 2005;4(1):57-9.

8. Jha A, Aryal G, Pant AD, Adhikari RC, Sayami G. Cytological diagnosis of bancroftian filariasis in lesions clinically anticipated as neoplastic. Nepal Med Coll J. 2008; 10(2):108-114.

9. Varghese T, Raghuveer CV, Pai MR, Bansal R. Microfilariae in Cytologic Smears. Acta cytologica. 1996 Jul 1;40(2):299-301.

10. Chakrabarti I, Das V, Halder B, Giri A. Adult filarial worm in the aspirate from a breast lump mimicking fibroadenosis. Tropical parasitology. $2011 \mathrm{Jul} ; 1(2): 129-31$.

11. Lahiri VL. Microfilariae in nipple secretion. Acta Cytologica. 1975; 19:154-5. 